\title{
AVALIAÇÃO DA QUALIDADE AMBIENTAL DE ECOSSISTEMAS COSTEIROS ARTICULADOS COM PROCESSOS DE EDUCAÇÃO AMBIENTAL: O USO DE INDICADORES DE QUALIDADE DA ÁGUA POR ALUNOS DE UMA ESCOLA PÚBLICA DO MUNICÍPIO DE GAROPABA, SC
}

\author{
ASSESSMENT ENVIRONMENTAL QUALITY OF COASTAL ECOSYSTEM \\ ARTICULATED WITH ENVIRONMENTAL EDUCATION PROCESSES: THE \\ USE OF WATER QUALITY INDICATORS BY STUDENTS OF A PUBLIC \\ SCHOOL IN CITY OF GAROPABA, SC
}

\author{
Patricia Darolt de Costa ${ }^{1}$ \\ Carlyle Torres Bezerra Menezes ${ }^{1}$
}

\begin{abstract}
Resumo
Este projeto direcionou-se ao estudo e aplicação de um instrumento de avaliação do estado atual da qualidade da água de um ecossistema aquático, formado pela micro bacia da Lagoa das Capivaras, localizada em Garopaba, SC. O estudo teve como objetivo alcançar uma melhor percepção ambiental por parte dos alunos de uma escola pública de ensino médio, por meio de sensibilização ambiental na perspectiva de reversão dos processos de degradação em que a Lagoa está submetida. O método utilizado contribuiu para o fortalecimento de metodologias participativas e a popularização de conhecimentos científicos.
\end{abstract}

Palavras-chave: Ecossistema costeiro, Qualidade Ambiental, Gestão Integrada e participativa.

\begin{abstract}
This project was directed to the study and application of an instrument to assess the current state of the an aquatic ecosystem quality, formed by micro basin of the Lagoon of Capybara, located in Garopaba, SC. The study aimed to achieve better environmental perception of students from a public high school, through environmental awareness with a view to reversing the degradation processes that the lagoon is submitted. The method used contributed to the strengthening of participatory methodologies and popularization of scientific knowledge.
\end{abstract}

Keywords: Coastal ecosystem, Environmental Quality, Integrated Management and participatory.

\section{Introdução}

As ações do homem se caracterizam pela agressiva supressão das bases de sustentação do seu próprio desenvolvimento, fato que tem se verificado por processos destrutivos que afetam o equilíbrio natural do ambiente, interferem negativamente nos processos ecológicos essenciais e, diretamente ou como consequência, reduzem a biodiversidade (VIO, 2001).

\footnotetext{
${ }^{1}$ Programa de Pós-graduação em Ciências Ambientais - PPGCA, Universidade do Extremo Sul Catarinense - UNESC.E-mail: paty_darolt@ hotmail.com
} 
Muitas das atividades dos homens afetam direta ou indiretamente os recursos hídricos. Estes vêm sendo alterados por meio dos impactos ambientais decorrentes de atividades mineradoras, pecuária, construção de barragens e represas, lançamento de efluentes domésticos, agrícolas e industriais sem o devido tratamento, pesca predatória, desmatamento e uso inadequado do solo, ocupação desordenada, entre outras. Essas atividades tem se expandido sem um controle maior do meio ambiente, sendo que os ambientes aquáticos, devido às suas características de proporcionar uma maior difusão dos poluentes, terminam contribuindo para que os contaminantes lançados mesmo que em águas interiores, sejam transportados até a foz dos rios de vertente atlântica, portanto para o ambiente marinho-costeiro (WASSERMAN \& WASSERMAN, 2008).

A Zona Costeira pode ser entendida como borda oceânica de continentes e ilhas. É a região da interface entre componentes do continente, oceano e a atmosfera. As mudanças graduais nos processos naturais sejam eles físicos, químicos ou biológicos, podem acarretar impactos nas funções e no uso deste ambiente. (MARRONI; ASMUS, 2005). Dentro do limite da zona costeira existem as lagoas costeiras, que constituem ecossistemas de grande produtividade (SANTOS, 2008). As lagoas costeiras são ecossistemas aquáticos de grande importância, uma vez que constituem interfaces entre zonas costeiras, águas interiores e águas costeiras marinhas. Não só cada ecossistema destes é peculiar e único mas, a compreensão do conjunto de lagoas costeiras, em determinadas regiões, é um desafio científico extremamente importante para o Brasil (ESTEVES,1998b).

Um ambiente costeiro bastante afetado é a Lagoa das Capivaras, situada no município de Garopaba, SC. De acordo com estudos anteriores (MENEZES; DAMÁSIO, 2005; MENEZES; DAMINELLI, 2007; MARIANO, 2010), esta lagoa encontra-se em um avançado estado de degradação, decorrente do lançamento de esgotos domésticos em especial sem tratamento, da supressão da vegetação nativa, aterro das margens, além da ocupação urbana desordenada no seu entorno, ocasionando então a contaminação de suas águas. $\mathrm{O}$ quadro final resultante traduz-se em um alto índice de coliformes fecais, elevada concentração de matéria orgânica e um processo que se encontra em acelerado estado de eutrofização.

A falta de políticas consistentes no que diz respeito às questões de saneamento ambiental e de saúde pública, aliada à falta de participação e mobilização efetiva da sociedade na busca de melhorias da qualidade do ambiente de vida e da preservação dos ecossistemas, vem contribuindo para os graves desequilíbrios e processos de degradação 
do meio ambiente. São por estes motivos, que o projeto de pesquisa em questão foi realizado para dar continuidade aos projetos já realizados na área escolhida. O objetivo do trabalho foi o de contribuir para o processo de educação e sensibilização ambiental de alunos do ensino médio de uma escola pública do Município Garopaba, com enfoque à gestão integrada, a fim de torna-los multiplicadores da gestão ambiental e auxiliar na reversão da degradação da Lagoa das Capivaras.

Um dos passos para alcançar um equilíbrio entre o homem e o ambiente em ecossistemas costeiros é investir na educação ambiental, que tem como uma das finalidades sensibilizar as pessoas em relação ao meio ambiente e aos impactos que este sofre. Isso por meio da capacitação e incentivo para que as mesmas almejem pela resolução de problemas atuais e pela preservação do meio e dos recursos naturais, garantindo assim um futuro sustentável. É preciso, então, fortalecer a consciência crítica da população para que a mesma participe ativamente por melhores condições de vida (MADUREIRA; TAGLIANI, 1997).

\section{Material e Métodos}

A área de estudo, a Lagoa das Capivaras, situada na região central do município de Garopaba, Santa Catarina, foi definida em função da relevância ambiental de um ambiente lagunar o qual está inserido em uma área urbana que sofre pressão do elevado crescimento urbano de forma desordenada, conforme pode ser visualizada na Figura 1.

A Lagoa das Capivaras, além de suas funções ecológicas, possui grande importância histórica e cultural para a população local. Apesar de sua relevante riqueza ambiental, encontra-se atualmente cercada pela intensa pressão ambiental decorrente da especulação imobiliária e a ausência de saneamento básico devido à falta de políticas públicas ambientais.

O ecossistema lagunar objeto da pesquisa se estende por áreas de planícies marinhas e fluviais, situando-se entre as bacias hidrográficas do rio D`Una, em Imaruí, e do rio da Madre, em Palhoça. Encontra-se situada bem ao centro do município, possuindo uma área total de aproximadamente 20 hectares, com a lâmina d'água correspondendo a equivalente a 12 hectares e profundidade variando de 2 a 5 metros, dependendo do processo de assoreamento ocorrido sobre os vários pontos da lagoa (ESTEVES, 1998a).

Figura 1: Lagoa das Capivaras e crescimento urbano no seu entorno 


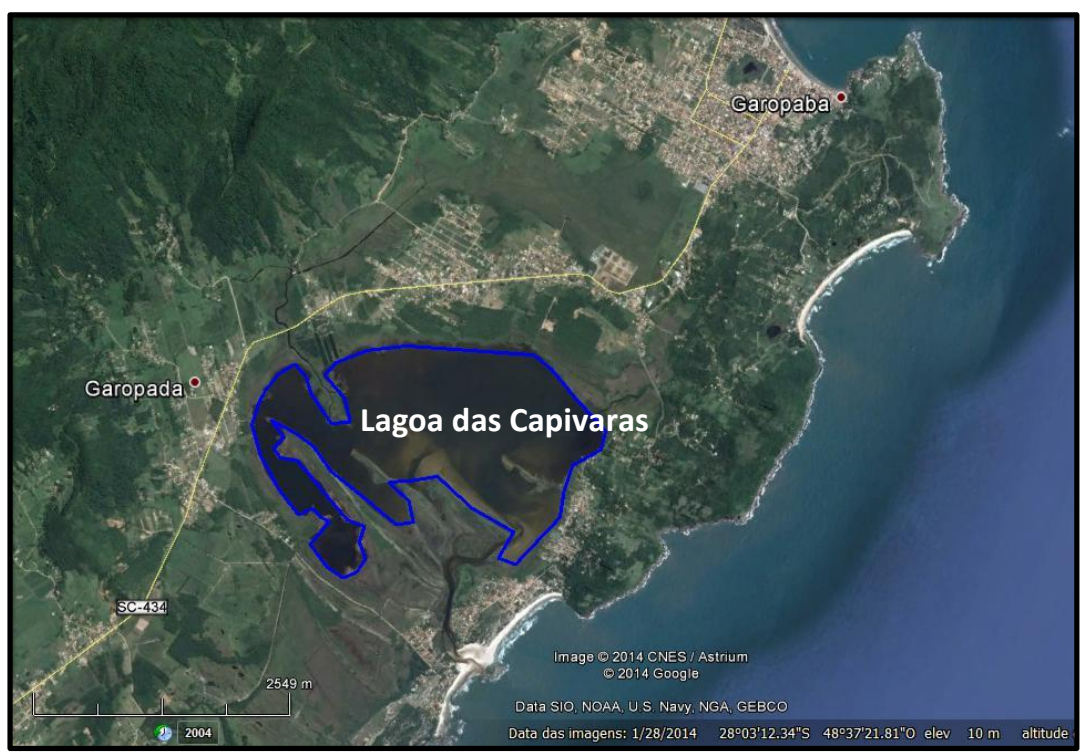

Fonte: Adaptada de Google Earth, 2014.

A Lagoa está inserida na interface entre uma Unidade de Conservação Integral, o Parque Estadual da Serra do Tabuleiro, e uma importante Unidade de Conservação de Uso Sustentável, a Área de Proteção Ambiental da Baleia Franca, ambas inseridas no âmbito do sistema de Unidades de Conservação do ICMBio (Instituto Chico Mendes de Conservação da Biodiversidade).

O público alvo foi definido a partir da seleção de uma escola de ensino médio de Garopaba. A escola foi selecionada em função da proximidade da lagoa bem como da existência de trabalhos anteriores de educação ambiental envolvendo professores e alunos do ensino médio articulados com professores e alunos de ensino superior, no caso a Universidade do Extremo Sul Catarinense.

O reconhecimento da área de estudo foi realizado por visitas a campo e levantamento expedito para obtenção de dados preliminares. Com a indicação da escola e pontos focais, correspondendo a lideranças comunitárias e professores, foi possível a obtenção de informações importantes no que se refere a situação atual e perspectivas quanto ao estado atual da lagoa das Capivaras e seu nível de degradação.

Essa etapa importante do projeto corresponde a um diagnóstico ambiental acerca das principais características ambientais da área onde está localizada a micro-bacia formada pela lagoa das Capivaras. A Figura 2 ilustra os aspectos gerais da Lagoa das Capivaras, e pode-se perceber o "superdesenvolvimento" de espécies macrófitas aquáticas sobre a superfície da Lagoa, evidenciando o processo de eutrofização da mesma. 
Figura 2. Lagoa das Capivaras eutrofizada

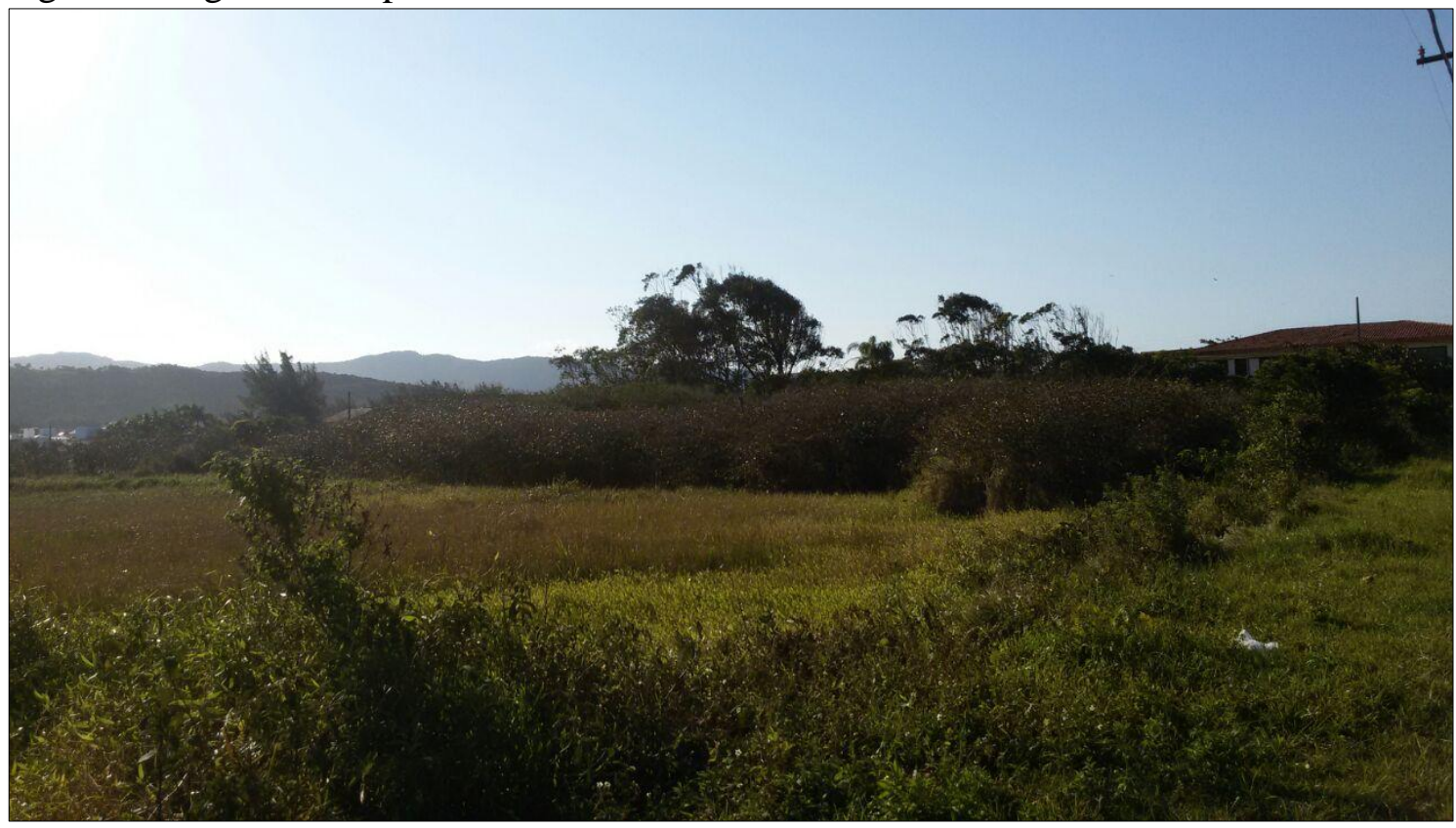

Fonte: Autores.

Foi utilizado um conjunto de componentes, para ensaios em campo, de análise de qualidade de água, denominado de ecokit, que permite em processos educativos uma boa aproximação dos alunos com relação a indicadores da qualidade da água químicos, físico-químicos e microbiológico. Esses ecokits são compostos por materiais e reagentes para análises imediatas de alguns indicadores ambientais de qualidade da água. Os indicadores selecionados para capacitação dos alunos e professores para análise da água e a percepção ambiental sobre o estado atual do sistema lagunar objeto da pesquisa foram os seguintes: $\mathrm{pH}$, oxigênio dissolvido, cloreto, dureza total, amônia, ferro e turbidez.

Para validação e comparação dos resultados obtidos pelo grupo de alunos da escola, foi programado uma amostragem e análise da água da lagoa pelo laboratório de águas e efluentes no IPAT (Instituto de Pesquisas Ambientais e Tecnológicas).

\section{Resultados e Discussão}

No desenvolvimento da metodologia proposta foram realizadas oficinas com os alunos do primeiro ano do ensino médio de uma escola pública do município de Garopaba (SC). Em uma primeira etapa ocorreu a apresentação do projeto com a demonstração do funcionamento do ecokit e explicação do significado dos parâmetros químicos e físico-químicos. Posteriormente ocorreu a cessão deste ecokit para a escola, 
de maneira que alunos e o professor responsável se apropriassem dos conceitos teóricos e práticos por meio desse instrumento de avaliação da qualidade ambiental.

O ecokit permaneceu na escola sob a supervisão de um professor responsável pelo acompanhamento, amostragem e realização das análises com os alunos, se tornando um importante instrumento de estudo para o desenvolvimento da percepção e sensibilização de alunos e professores envolvidos no projeto. A amostragem realizada pelo grupo de alunos foi realizada a cada três meses, durante o ano de realização do projeto.

Os resultados obtidos das análises de qualidade de água da Lagoa das Capivaras, tanto aqueles obtidos pelo grupo de alunos e professores, quanto àqueles obtidos por meio da coleta e análise pelo IPAT/UNESC estão descriminados na tabela abaixo:

Tabela 01: Resultados das análises da água da Lagoa das Capivaras

\begin{tabular}{lcccccc}
\hline \multirow{2}{*}{ Parâmetros } & $\begin{array}{l}\text { Análise } \\
\text { IPAT }\end{array}$ & $\begin{array}{l}\text { Análises feitas com o ecokit pelos } \\
\text { alunos }\end{array}$ & & & & \\
& & $\mathbf{1}$ & $\mathbf{2}$ & $\mathbf{3}$ & $\mathbf{4}$ & $\mathbf{5}$ \\
Cloreto (mg/L) & 15,5 & 40,0 & 40,0 & 40,0 & 30,0 & 40,0 \\
Dureza total (mg/L) & 24 & 40,0 & 40,0 & 40,0 & 30,0 & 30,0 \\
Oxigênio dissolvido & 8,3 & 8,0 & 8,0 & 7,0 & 8,0 & 8,0 \\
(mg/L) & & & & & & \\
Amônia (mg/L) & 0,2 & 0,5 & 1,0 & 1,0 & 0,5 & 1,0 \\
Ferro (mg/L) & 2,52 & 0,25 & 0,25 & 0,25 & 0,25 & 0,25 \\
pH & 6,5 & 6,5 & 6,0 & 6,5 & 6,5 & 6,5 \\
Turbidez & 36,2 & 100,0 & 100,0 & 50,0 & 100,0 & 100,0 \\
\hline
\end{tabular}

Fonte: Autores.

O estudo comparativo entre os dados apresentados na tabela 01 permite algumas considerações importantes, ressalvando-se no entanto, que o objetivo maior dessa comparação não era quanto ao rigor em termos de procedimentos e padrões quantitativos, e sim quanto aos aspectos de apropriação do conhecimento por parte dos alunos e professores da escola participante do projeto.

Comparando os resultados, das análises realizadas, obtidos pelos alunos e pelo laboratório de águas e efluentes do IPAT, apenas dois parâmetros demonstraram uma relativa similaridade, sendo eles o $\mathrm{pH}$ e o oxigênio dissolvido, ocorrendo diferenças 
significativas nas análises de cloretos, dureza total, amônia, ferro e turbidez. No caso dos parâmetros onde ocorreram maiores diferenças quanto aos resultados obtidos, eles apontaram para a necessidade de ajuste tanto dos procedimentos para realização dos ensaios e manipulação dos reagentes utilizados, quanto para as características próprias desse tipo de instrumento de educação ambiental, no caso os ecokits, que não tem como objetivo principal um rigor maior quanto à precisão quantitativa para todos os parâmetros analisados.

Considerando os resultados obtidos nesta pesquisa e os registrados em estudos anteriores na Lagoa das Capivaras (MENEZES; DAMINELLI, 2007; MARIANO, 2010), com relação à qualidade da água e seu contínuo estado de degradação pelo fato de que esse ecossistema ainda recebe efluentes domésticos e industriais sem tratamento prévio, é de extrema importância a integração entre o poder público e a sociedade civil, assim para que se torne possível a interação entre crescimento econômico e preservação ambiental. Isso por meio do fortalecimento comunitário, com o desenvolvimento e implantação de políticas públicas ambientais de maneira a reverter o estado atual do ecossistema estudado, como citam Marroni e Asmus (2005), que apresentam uma proposta para o fortalecimento comunitário na gestão ambiental dos ecossistemas costeiros.

A pesquisa possibilitou uma maior compreensão acerca da situação atual de um ambiente costeiro por parte dos alunos de uma escola pública, e a sua integração com um grupo de pesquisas acadêmicas com vistas à realização de um diagnóstico ambiental preliminar. O kit também proporcionou um importante papel no processo de educação ambiental não formal, a qual enfatiza a sensibilização e o despertar da preocupação com o meio ambiente, permitindo que os alunos tivessem acesso a conceitos básicos em ciências e química de ambientes aquáticos e à realização de análise de água.

Os processos educativos aplicados constituíram-se de grande relevância e possuem considerável potencial para contribuir na reversão de degradação de ambientes costeiros. Esses processos auxiliam na sensibilização ambiental e na apropriação do conhecimento sobre importantes questões ambientais, promovendo um melhor entendimento e desenvolvimento de uma consciência crítica por parte dos alunos do ensino médio, no que diz respeito à reversão do atual estado de degradação do ecossistema costeiro estudado. O método utilizado contribuiu também para o fortalecimento de metodologias participativas e a popularização de conhecimentos científicos. 
Referências

BRASIL. Ministério do Meio Ambiente. Disponível em: <http://www.mma.gov.br/sitio/index.php?ido=conteudo.monta\&idEstrutura=119\&idCo nteudo=9677\&idMenu=11809> Acesso em março/2012.

ESTEVES, F. A. Lagoas Costeiras: origem, funcionamento e possibilidades de manejo. In: ESTEVES, F. A. (ed.) Ecologia do Parque Nacional da Restinga de Jurubatiba e do município de Macaé (RJ). Rio de Janeiro: Núcleo de Pesquisas Ecológicas de Macaé - NUPEM/ UFRJ, 1998a. p.63-87.

Lagoa Imboassica: impactos antrópicos, propostas mitigadoras e sua importância para a pesquisa ecológica. In: ESTEVES, F. A. (ed.) Ecologia do Parque Nacional da Restinga de Jurubatiba e do município de Macaé (RJ). Rio de Janeiro: Núcleo de Pesquisas Ecológicas de Macaé - NUPEM/ UFRJ, 1998b. p.401-429.

MADUREIRA, M. S. P.; TAGLIANI, P. R. A. Educação ambiental não-formal em unidades de conservação federais na Zona Costeira Brasileira: uma análise crítica. Brasília: IBAMA, 1997. 100 f. (Série Meio ambiente em debate, 16).

MENEZES, C.T.B; DAMASIO, M. Educação Ambiental e Gestão de Ambientes Costeiros no município de Garopaba, Santa Catarina. Criciúma: Programa de Iniciação Cientifica (PIC V) - Relatório Final, 2005.

MENEZES, C.T.B; DAMINELli, S. Gestão Pública em Ambientes Costeiros: O monitoramento da Lagoa das Capivaras no Município de Garopaba, SC. Anais do XII Congresso Latino-Americano de Ciências Do Mar, Florianópolis, SC, 15 à 19/04/2007.

\section{MARIANO, N. M. Diagnóstico ambiental como subsídio para}

recuperação de lagoas costeiras: estudo de caso da lagoa das capivaras - Garopaba - SC. 2010. 98f. Dissertação (Mestrado em Ciências Ambientais). Universidade do Extremo Sul Catarinense, Criciúma.

MARRONI, E. V.; ASMUS, M. L. Gerenciamento Costeiro: Uma proposta para o fortalecimento comunitário na gestão ambiental. Pelotas: Editora da União Sul-America de Estudos da Biodiversidade - USEB, 2005. 149p.

SANTOS, M. C. Contribuição à gestão das lagoas costeiras: conhecimento tradicional, técnico e científico associado ao manejo dos recursos naturais da Lagoa de Carapebus, Parque Nacional da Restinga de Jurubatiba - RJ. 2008. 135 f. Dissertação (Mestrado em Engenharia Ambiental). Centro Federal de Educação Tecnológica de Campos, 2008.

VIO, A. P. de A.; BENJAMIN, A. H. (Coord.). Direito ambiental das áreas protegidas: o regime jurídico das unidades de conservação. Rio de Janeiro: Forense Universitária, 2001. 546 p.

WASSERMAN, J. C.; WASSERMAN; M. A. Comportamento dos Metais em Sedimentos. In: BAPTISTA, J. A; WALLNER-KERSANACH, M.; PATCHINEELAM, S.M. (Orgs). Poluição Marinha. Rio de Janeiro: Interciência, 2008. 